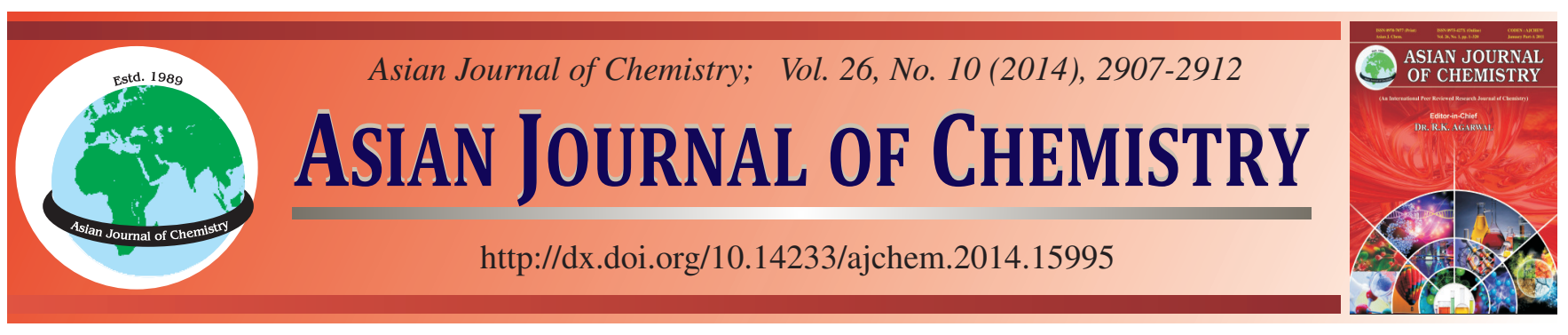

\title{
Synthesis of 1,3-Dichloropropanol from Glycerol Using Muriatic Acid as Chlorinating Agent
}

\author{
Herliati $^{1,2}$, Robiah Yunus ${ }^{1,3,{ }^{*}, \text { Umer Rashid }^{3, *}, \text { Zurina }^{2} \text { Zainal Abidin }}{ }^{1}$ and Intan Salwani Ahamad ${ }^{1}$
}

${ }^{1}$ Department of Chemical and Environmental Engineering, Faculty of Engineering, Universiti Putra Malaysia, 43400 UPM Serdang, Selangor, Malaysia

${ }^{2}$ Department of Chemical Engineering, Faculty of Industrial Technology, Universitas Jayabaya, Pulomas 13210, Indonesia

${ }^{3}$ Institute of Advanced Technology, Universiti Putra Malaysia, 43400 UPM Serdang, Selangor, Malaysia

*Corresponding authors: Fax: +60 03 89467004; Tel: +60 38946 7533; E-mail: robiah@eng.upm.edu.my; umer.rashid@yahoo.com

Today, one of the problems associated with biodiesel production is the availability of high amount of glycerol byproduct. Among the various possibilities, technology to convert glycerol to dichloropropanol has diverted our attention. Dichloropropanol an important raw material for epichlorohydrin production was successfully synthesized via hydrochlorination reaction of glycerol with aqueous hydrogen chloride to produce 1,3-dichloropropanol. Experimental study was carried out under temperatures ranged; 80 to $120{ }^{\circ} \mathrm{C}$, reactant molar ratio; $1: 16$ to $1: 32$ and various carboxylic acid catalysts. The optimal reaction conditions were: temperature, $110{ }^{\circ} \mathrm{C}$; reactant molar ratio glycerol to $\mathrm{HCl}, 1: 24$; catalyst, malonic acid; and time duration, $3 \mathrm{~h}$.

Keywords: Dichloropropanol, Epichlorohydrin, Hydrochlorination, Carboxylic acid, Muriatic acid.

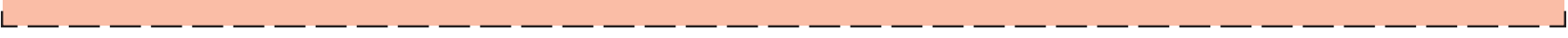

\section{INTRODUCTION}

The synthesis of dichloropropanol (DCP) through hydrochlorination of glycerol has become increasingly important. Dichloropropanol is an intermediate in the production of epichlorohydrin which is applied in various fields, such as epoxide resin and several pharmaceutical products ${ }^{1}$. The conventional method to prepare dichloropropanol involves two steps reactions comprises the first reaction is the preparation of allyl chloride by reacting propylene and chlorine at high operating temperature followed by chlorination of allyl chloride to produce dichloropropanol (Fig. 1) 2,3 $^{2}$. However the above process is not economically viable because the method utilizes propylene, a high cost non-renewable feedstock.

Glycerol, the byproduct of the process during the production of biodiesel, a considerable amount of glycerol $(10 \%)$ is formed as a by-product ${ }^{4}$. Glycerol is also considered to be a potential low cost renewable feed stock ${ }^{5}$. A process for the conversion of glycerol to a mixture of dichloropropanol compounds, 1,3-dichloropropanol and 1,2-dichloropropanol, is known as hydrochlorination ${ }^{6}$ (Fig. 2). The above reaction can be carried out in the presence of gaseous hydrogen chloride, in large excess and a carboxylic acid catalyst ${ }^{6-8}$.

The use of large excess amount of anhydrous hydrogen chloride may not be economically viable ${ }^{9}$. According to the above process route, for hydrochlorination of glycerol, aqueous

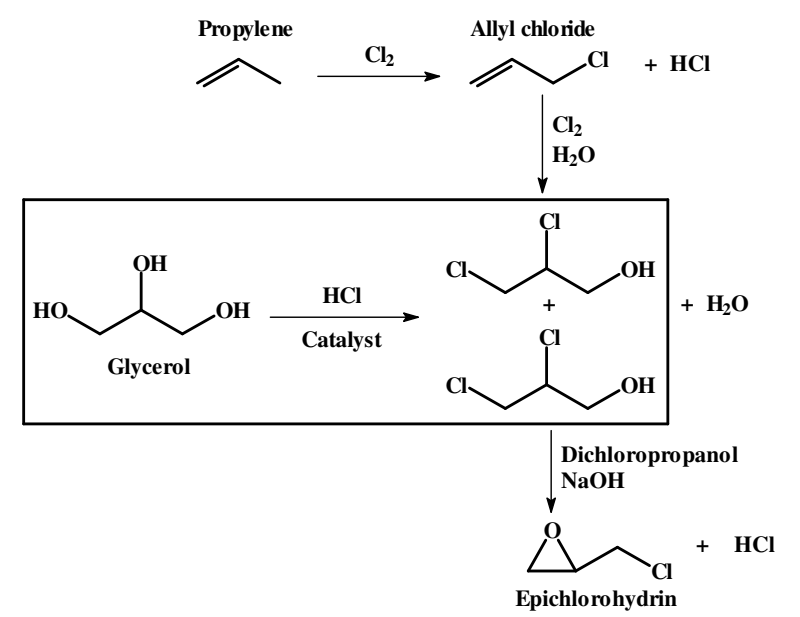

Fig. 1. Preparation of epichlorohydrin via allyl chloride and via dichloropropanol $^{3}$<smiles>OCC(O)CO</smiles>

Glycerol<smiles>OCC(Cl)CCl</smiles>

1,3-DCP
1,2-DCP
Fig. 2. Hydrochlorination of glycerol ${ }^{10}$ 
hydrogen chloride of 28 to $37 \%$ by weight can also be used as a chlorinating agent under atmospheric condition. The reaction can be carried out in either batch or continuous mode by vigorously stirring within temperature range of 100 to $120{ }^{\circ} \mathrm{C}$. However, other hydrochlorination studies to produce dichloropropanol were poorly developed around aqueous hydrogen chloride as a chlorination agent.

The main objective of this study was to develop a process for the synthesis of 1,3-dichloropropanol through hydrochlorination glycerol and $\mathrm{HCl}$ in the presence of carboxylic acid. The $\mathrm{HCl}$ selected was muriatic acid (hydrogen chloride, $37 \%$ w/wt.) due to its good performance as chlorinating agent ${ }^{9,10}$. Firstly, our experimental work focused on the performances of catalysts containing carboxylic acid groups of which having a lower volatility than acetic acid, such as propionic acid, malonic acid and lactic acid. After identifying the best catalyst for the synthesis, the experiments were then directed towards investigating the effects of operating parameters such as reactant molar ratio and temperature of reaction on the reaction yields. Our present results were also compared with experimental data 7 and simulation study using Aspen Plus ${ }^{\mathrm{TM}} 11$.

\section{EXPERIMENTAL}

Commercially available carboxylic acid catalysts namely acetic acid, propionic acid, lactic acid and malonic acid, glycerol and muriatic acid were purchased from Merck Chemical Co. While 1,3-dichloropropanol for GC standard calibration was obtained from Sigma Aldrich Co. Singapore.

Experimental run: First set of experimental runs focused on screening of the best catalyst which were conducted at a molar ratio of glycerol and muriatic acid of 1:16 and $8 \%$ catalyst by mole as recommended by Yunus et al. ${ }^{11}$. Four types of carboxylic acid, namely propionic acid, malonic acid, lactic acid and acetic acid, were investigated at $90{ }^{\circ} \mathrm{C}$ with respect to the acetic acid low volatility $\left(117^{\circ} \mathrm{C}\right)$. Then experiments were done to observe the effects of reactant molar ratio on the process at values ranged from 1:16 to $1: 32$. The experiments were conducted at $120 \pm 5^{\circ} \mathrm{C}$ using the best selected catalyst from the previous screening experiments. After which, the experiments were performed to examine the effect of temperature on conversion of glycerol and selectivity of 1,3-dichloropropanol at 80, 90, 100110 and $120^{\circ} \mathrm{C}$.

Experimental setup:The reactions were performed in a $250 \mathrm{~mL}$ three-neck flask equipped with a thermometer, a sampling port and a reflux condenser. The condenser was connected to an accumulator. The reactor was immersed in a temperature controlled oil bath at constant stirring by the magnetic stirrer. Initially, the reactants comprised of glycerol and aqueous hydrogen chloride solution $37 \% \mathrm{w} / \mathrm{w}$ (chlorination agent) was loaded into glass reactor. After the homogeneous solution reached certain temperature (in the range of 80 to $120{ }^{\circ} \mathrm{C}$ ) under vigorous stirring, aqueous hydrogen chloride, chlorination agent, were slowly added to the mixture followed by the catalyst. In this way, the catalyst would be uniformly distributed in the reaction media which increase the effective surface area provided by the catalyst for the reaction. The reaction in the presence of catalyst was conducted for $3 \mathrm{~h}$. For analysis of reaction products, gas chromatography method was used throughout the experiments.
Sample preparation and analysis: About $3 \mathrm{~mL}$ of sample was treated with $0.5 \mathrm{~g}$ of the mentioned salt and kept at $100{ }^{\circ} \mathrm{C}$ for $0.5 \mathrm{~h}$ in order to remove the entire water residues ${ }^{7}$. The sample was then filtered with Whatman filter paper in order to separate the precipitate formed and the clarified solution was then analyzed by using gas chromatographic/mass spectrometry (GC/MS).

Quantitative analyses were carried out using GC/MS under the following conditions: column, Capillary HP Wax; stationary phase; length $=25 \mathrm{~m}$; i.d. $=0.25 \mathrm{~mm}$; film thickness $=$ $0.25 \mu \mathrm{m}$; Ionization mode; helium as gas carrier; injector temperature $=250{ }^{\circ} \mathrm{C}$; detector temperature $=230{ }^{\circ} \mathrm{C}$; temperature ramp $=1 \mathrm{~min}$ at $80^{\circ} \mathrm{C}$; heating rate $=6^{\circ} \mathrm{C} / \mathrm{min}$ to $150^{\circ} \mathrm{C}$, then $3{ }^{\circ} \mathrm{C} / \mathrm{min}$ up to $190{ }^{\circ} \mathrm{C}$, then hold for $1 \mathrm{~min}$ at finally $=$ $240{ }^{\circ} \mathrm{C}$. The sample of the reaction mixture was first diluted with methanol in a volumetric ratio of 1:20. The injected volume of the obtained solution was $1 \mu \mathrm{L}$.

The effects of reactant mol ratio and operating temperature on both conversion of glycerol and selectivity of 1,3-dichloropropanol were examined by using aforementioned procedure. Eqn (i) and (ii) were used to calculate the conversion of glycerol and selectivity of dichloropropanol respectively:

$$
\begin{gathered}
\begin{array}{c}
\text { Conversion of } \\
\text { glycerol }(\%)
\end{array}=\frac{\text { Moles of glycerol reached }}{\text { Mole of glycerol supplied }} \times 100 \\
\begin{array}{c}
\text { Moles of dichloro- } \\
\text { propanol produced }
\end{array} \\
\begin{array}{c}
\text { Selectivity of } \\
\text { DCP }(\%)
\end{array}
\end{gathered}=\frac{100}{\text { Mole of glycerol reacted }}
$$

\section{RESULTS AND DISCUSSION}

Screening of catalyst: The selection of the best catalyst from carboxylic acid groups is crucial to obtain a good selectivity from the reaction. To observe the performances of the selected carboxylic acid catalysts on the conversion and also selectivity, four experiments were conducted using acetic acid, propionic acid, lactic acid and malonic acid.

The screening of the catalyst was conducted initially by running the reaction between aqueous hydrogen chloride and glycerol without the presence of catalyst. It was observed that without catalyst there was no conversion of glycerol at all. After that, the experimental runs were directed towards finding the best catalyst among the four selected carboxylic acids of which having a lower volatility than acetic acid (Table-1). From the results, it was observed that malonic acid was the best catalyst for the conversion of glycerol to 1,3-dichloropropanol. Malonic acid has relatively lower volatility of which enabled the reaction to be conducted at higher temperatures without appreciable loss of catalyst. In general, the conversion of glycerol was almost complete after $3 \mathrm{~h}$ using these catalysts. In addition, the selectivity of the reaction was also analyzed based on the concentration of 1,3-dichloropropanol which was at $44 \%$ by moles using malonic acid catalyst. The maximum selectivity of dichloropropanol obtained in the earlier work was $21 \%$ higher compared to the earlier study by Tesser et al. ${ }^{7}$. On the other hand, Yunus and Herliati ${ }^{11}$ demonstrated that up to $70 \%$ selectivity of dichloropropanol could be obtained from simulation study using Aspen Plus ${ }^{\mathrm{TM}}$. However, the previous result was obtained using gaseous hydrogen chloride as a 


\begin{tabular}{|c|c|c|c|c|}
\hline \multicolumn{5}{|c|}{$\begin{array}{c}\text { TABLE-1 } \\
\text { EXPERIMENTAL RUNS FOR CATALYST SCREENING }\end{array}$} \\
\hline Catalyst & Amount of catalyst (g) & $\begin{array}{c}\text { Glycerol conversion after } \\
0.5 \mathrm{~h}(\%) \\
\end{array}$ & $\begin{array}{l}\text { Glycerol conversion } \\
\text { after } 3 \mathrm{~h}(\%)\end{array}$ & $\begin{array}{l}\text { Selectivity to } \\
\text { 1,3-dichloropropanol at } 3 \mathrm{~h}(\%)\end{array}$ \\
\hline AA & 15.73 & 85.28 & 99.23 & 13.95 \\
\hline LA & 15.70 & 56.59 & 97.83 & 11.41 \\
\hline MA & 16.19 & 82.01 & 99.10 & 44.34 \\
\hline PPA & 15.84 & 88.31 & 96.56 & 28.96 \\
\hline \multicolumn{5}{|c|}{ Products distribution after $3 \mathrm{~h}$ of reaction $(\%)$ by moles } \\
\hline Catalyst & Glycerol & $1-\mathrm{MCP}$ & $1,3-\mathrm{DCP}$ & 1,2-DCP \\
\hline AA & 0.88 & 29.21 & 67.82 & 2.09 \\
\hline LA & 0.65 & 31.30 & 66.95 & 1.10 \\
\hline MA & 0.90 & 21.54 & 73.31 & 4.24 \\
\hline PPA & 0.37 & 22.80 & 73.75 & 3.08 \\
\hline
\end{tabular}

chlorination agent instead of liquid. Therefore, in terms of cost, the use of liquid chlorination agent in this study can be a viable method compared to others because the cost of our technology is lower. But this conclusion should be supported by a more comprehensive study.

The results for glycerol conversion after $0.5 \mathrm{~h}$ of reaction and conversion after $3 \mathrm{~h}$ and selectivity towards the desired product 1,3-dichlopropanol are shown in the Table-1. The best catalyst should have the character of high activity and high selectivity and, low volatility in order to ensure minimum losses. The product distribution profiles obtained after $3 \mathrm{~h}$ of reaction for all the screened catalysts are also shown in Table- 1 .

In this reaction carboxylic acid containing carboxyl group acts as electrophile, thus the strongest acid shall be the most effective ${ }^{12}$. As can be seen in Table- 1 the trend of findings indicate that the Brønsted acid sites of malonic acid $\left.\left[\mathrm{CH}_{2}(\mathrm{COOH})_{2}\right)\right]$ catalyst is favorable to the said reaction. The acidity $\left(\mathrm{pK}_{\alpha}\right)$ of those selected catalyst, propionic acid, acetic acid, lactic acid and malonic acid are 4.8, 4.76, 3.9 and $2.83 \%$, respectively. Thus, it is concluded that the acid strength of the carboxyl group significantly influenced the catalytic activity. This conclusion is supported well with the previous study by Lee et $a l .^{3}$. It was reported that increasing acid strength of the catalyst will increase selectivity towards 1,3-dichloropropanol ${ }^{3}$. Similarly, acid property of the catalyst played an important role in the hydrochlorination reaction of glycerol to dichloropropanol $^{6,8}$.

Moreover, even though the price of malonic acid is 3.5 fold over than the acetic acid the high volatility of acetic acid renders the acid to be not suitable for operation at high temperature. This is evidenced from the results shown in Table-1, where though the conversion of glycerol for acetic acid is high (99\%), most of the products remained as monochloropropanol (1-MCP). On the contrary, malonic acid can allow one to perform the reaction at higher temperature without appreciable loss of catalyst due to its less volatility, thus higher selectivity.

Effect of reactant molar ratio:Under the state of a chemical equilibrium system, based on Le-Chatelier's Principle, one of the methods to shift the reaction towards the forward direction is by using excess amount of either glycerol or hydrogen chloride. Hydrogen chloride functions as a nucleophilic for hydrochlorination reaction of glycerol through substitution of nucleophilic $S_{N} 2$. The said ion attacks the nucleophile onto the glycerol containing electrophilic carbon. Thus, we chose hydrogen chloride as an excess reactant. The stoichiometric molar ratio between the glycerol and aqueous hydrogen chloride is $1: 2$. For catalyst screening, the molar ratio of $1: 16$ (glycerol: $\mathrm{HCl}$ ) was used throughout the experiments to evaluate the effect on both extent of reaction and selectivity. This is to ensure that the reaction was unconstrained by the effect of excess reactant. The investigation on the effects of glycerol:HCl molar ratio on conversion to 1,3-dichloropropanol was carried out at $120{ }^{\circ} \mathrm{C}$ and atmospheric condition for $3 \mathrm{~h}$. The amount of catalyst was maintained at $8 \%$ by mole in all experiments.

The effects of various molar ratio of glycerol: $\mathrm{HCl}$ on product composition are shown in Tables 2 to 6 . The results are summarized in Fig. 3 which shows that there is no significant effect of increasing molar ratio on the conversion of 1,3-dichloropropanol. Slightly higher percentage of 1,3dichloropropanol was obtained at molar ratio of 1:20 and 1:24. However, the difference was so small (42.79 and $43.12 \%$ ) that no conclusion could be withdrawn from the study. These results are strongly in agreement with the results from Aspen PlusTM on hydrochlorination reaction between glycerol and gaseous hydrogen chloride ${ }^{11}$. According to Aspen Plus ${ }^{\mathrm{TM}}$ simulation, on both extent of reaction and yield for 1,3-

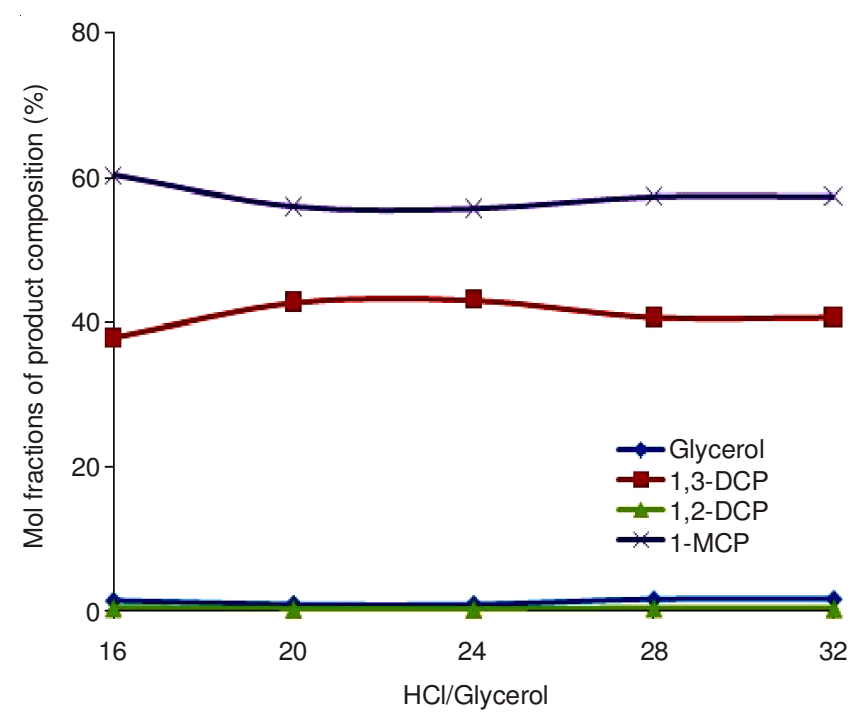

Fig. 3. Effect of molar ratio on hydrochlorination of glycerol 


\begin{tabular}{ccccc}
\hline \multicolumn{5}{c}{ TABLE-2 } \\
& EXPERIMENTAL RUN WITH MALONIC ACID AT HCl/GLYCEROL (1:16) \\
\hline $\mathrm{t} / \mathrm{s}$ & Glycerol $(\%)$ & $1-\mathrm{MCP}(\%)$ & $1,3-\mathrm{DCP}(\%)$ & $1,2-\mathrm{DCP}(\%)$ \\
\hline 0 & 100 & 0 & 0 & 0 \\
15 & 78.82383 & 20.24625 & 0.91992658 & 0.009993 \\
30 & 58.29827 & 38.01886 & 3.643298551 & 0.039578 \\
60 & 27.33296 & 59.99316 & 12.53767613 & 0.136213 \\
120 & 4.535865 & 64.9842 & 30.15230128 & 0.327637 \\
180 & 1.424873 & 60.28143 & 37.88204026 & 0.411659 \\
\hline
\end{tabular}

TABLE-3

EXPERIMENTAL RUN WITH MALONIC ACID AT HCI/GLYCEROL (1:20)

\begin{tabular}{ccccc}
\hline $\mathrm{t} / \mathrm{s}$ & Glycerol $(\%)$ & 1 -MCP $(\%)$ & $1,3-\mathrm{DCP}(\%)$ & $1,2-\mathrm{DCP}(\%)$ \\
\hline 0 & 100 & 0 & 0 & 0 \\
15 & 72.39915 & 26.0214 & 1.570343455 & 0.009097 \\
30 & 49.31057 & 44.98323 & 5.673328756 & 0.032869 \\
60 & 20.40683 & 62.58426 & 16.91092333 & 0.097982 \\
120 & 3.079151 & 61.32888 & 35.38691197 & 0.205057 \\
180 & 0.937568 & 56.01956 & 42.79487899 & 0.247992 \\
\hline Other experimental conditions: $\mathrm{T}=120^{\circ} \mathrm{C}$; glycerol loading $=12.6 \mathrm{~g}$; catalyst concentration $8 \%$ by moles
\end{tabular}

Other experimental conditions: $\mathrm{T}=120^{\circ} \mathrm{C}$; glycerol loading $=12.6 \mathrm{~g}$; catalyst concentration $8 \%$ by moles

TABLE-4

EXPERIMENTAL RUN WITH MALONIC ACID AT HCl/GLYCEROL (1:24)

\begin{tabular}{|c|c|c|c|c|}
\hline $\mathrm{t} / \mathrm{s}$ & Glycerol (\%) & $1-\mathrm{MCP}(\%)$ & $1,3-\mathrm{DCP}(\%)$ & $1,2-\mathrm{DCP}(\%)$ \\
\hline 0 & 100 & 0 & 0 & 0 \\
\hline 15 & 72.28072 & 25.97032 & 1.739960077 & 0.009 \\
\hline 30 & 49.05091 & 44.70929 & 6.207693855 & 0.032111 \\
\hline 60 & 20.16419 & 61.71202 & 18.03051817 & 0.093271 \\
\hline 120 & 3.067488 & 60.5044 & 36.24062448 & 0.187489 \\
\hline 180 & 0.927215 & 55.72525 & 43.12442411 & 0.223108 \\
\hline
\end{tabular}

TABLE-5

EXPERIMENTAL RUN WITH MALONIC ACID AT HCI/GLYCEROL (1:28)

\begin{tabular}{ccccc}
\hline $\mathrm{t} / \mathrm{s}$ & Glycerol $(\%)$ & 1 -MCP $(\%)$ & 1,3 -DCP $(\%)$ & 1,2 -DCP $(\%)$ \\
\hline 0 & 100 & 0 & 0 & 0 \\
15 & 81.9964 & 16.82906 & 1.164415631 & 0.010119 \\
30 & 62.69158 & 32.62958 & 4.638528652 & 0.04031 \\
60 & 30.65665 & 53.48985 & 15.71691292 & 0.136587 \\
120 & 5.362694 & 59.80184 & 34.53532582 & 0.300145 \\
180 & 1.619633 & 57.34563 & 40.68117832 & 0.353564 \\
\hline Other experimental conditions: $\mathrm{T}=120^{\circ} \mathrm{C} \cdot$ glycerol logding $=12.6 \mathrm{~g} \cdot$ catalyst concentration 8 \% by moles &
\end{tabular}

Other experimental conditions: $\mathrm{T}=120^{\circ} \mathrm{C}$; glycerol loading $=12.6 \mathrm{~g}$; catalyst concentration $8 \%$ by moles

\begin{tabular}{ccccc}
\multicolumn{5}{c}{ TABLE-6 } \\
EXPERIMENTAL RUN WITH MALONIC ACID AT HCl/GLYCEROL (1:32) \\
\hline t/s & Glycerol (\%) & 1 -MCP $(\%)$ & 1,3 -DCP $(\%)$ & 1,2 -DCP $(\%)$ \\
\hline 0 & 100 & 0 & 0 & 0 \\
15 & 81.93396 & 16.81054 & 1.245476493 & 0.010021 \\
30 & 62.53116 & 32.52075 & 4.908587897 & 0.039496 \\
60 & 30.50562 & 53.09582 & 16.26765917 & 0.130901 \\
120 & 5.438429 & 59.78702 & 34.49695871 & 0.277595 \\
180 & 1.654334 & 57.34258 & 40.67576627 & 0.327316 \\
\hline
\end{tabular}

Other experimental conditions: $\mathrm{T}=120^{\circ} \mathrm{C}$; glycerol loading $=12.6 \mathrm{~g}$; catalyst concentration $8 \%$ by moles

dichloropropanol, the maximum flow rate of gaseous hydrogen chloride was at $4 \mathrm{~g} / \mathrm{min}$ (molar ratio glycerol: $\mathrm{HCl} 1: 26$ ) which correspond to flow rate range from 2 to $24 \mathrm{~g} / \mathrm{min}$. After the maximum point, the effect of those parameters decreased significantly caused by spinning of agitator which will usually happen for gas-liquid reaction at flooding point condition ${ }^{11}$.

In contrast, Fig. 4 shows an interesting result where the yield of 1,3-dichloropropanol increased from 26.6 to $46.49 \%$ as the molar ratio increased from $1: 16$ to $1: 24$. After that point, there is no benefit of using higher ratio. At higher ratio, the reaction slowed down because of excessive presence of water in the reaction mixture, due to the use of aqueous hydrochloric acid and water that is formed as a consequence of the reaction itself $^{13}$. In addition, failure to remove the excessive water negatively impact on the second nucleophilic substitution $\mathrm{S}_{\mathrm{N}} 2$ that involves the attack of chlorine anion on the $\gamma$-position ${ }^{14}$. The removal of water from the reaction mixture, preferably by distillation under reduced pressure, in order to shift the 


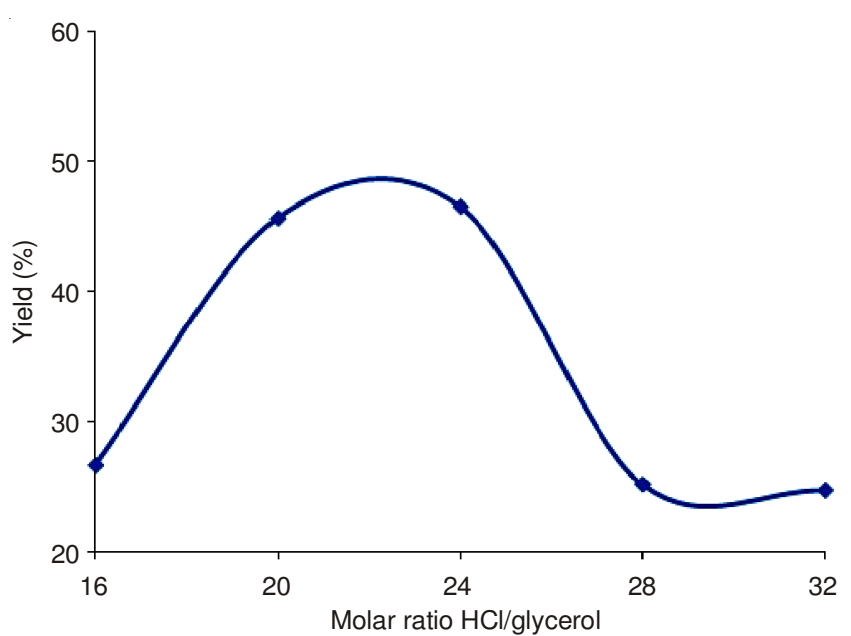

Fig. 4. Effects of molar ratio on yield of 1,3-dichloropropanol

reaction towards the forward direction would be considered for the subsequent study.

There is no similar experimental study that considers the effect of molar ratio on the hydrochlorination process. However, simulation study on the hydrochlorination of glycerol to 1,3dichloropropanol using gaseous hydrogen chloride, has been reported by Yunus and Herliati ${ }^{11}$. These results compared well with their findings as can be seen in Fig. 5. Thus, it can be concluded that employing a 12-fold excess of hydrogen chloride, as a hydrochlorination agent, can drive reaction to produce more 1,3-dichloropropanol. It is in line with the Le Chatelier's Principle which stated that more products will be formed by increasing reactant concentration and gradually the reverse rate will also increase because of the new products being formed. Consequently, the concentration of products will continue to rise until the reverse and forward rates equalizes (equilibrium state).

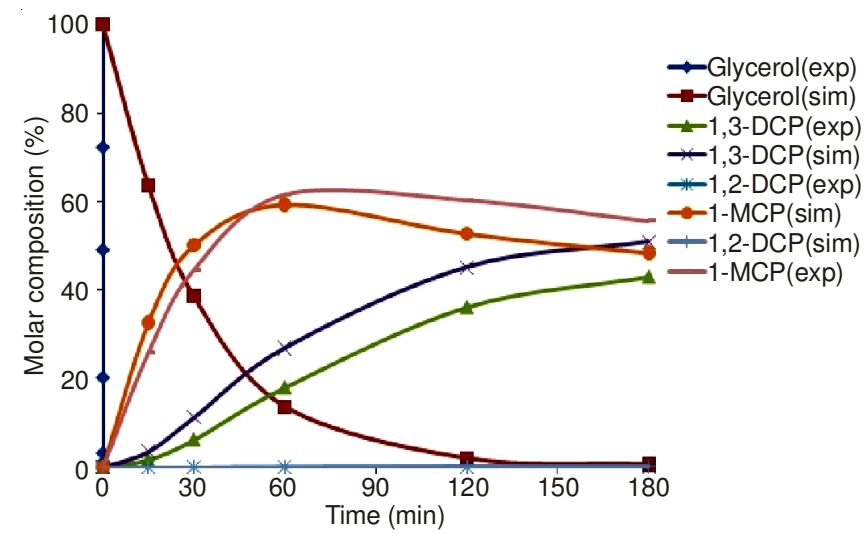

Fig. 5. Product distribution: Comparison between experimental data and simulation study by Yunus and Herliati ${ }^{11}$

Effect of temperature: The temperature range selected for this study was between 80 to $120{ }^{\circ} \mathrm{C}$. The reaction was conducted for $3 \mathrm{~h}$ using $8 \%$ malonic acid (by mole) as the catalyst and 1:24 molar ratio of glycerol to $\mathrm{HCl}$. The aim of this study was to observe the effect of temperature on the product composition, conversion of glycerol and yield of 1,3dichloropropanol. The distribution product at five different temperatures on the hydrochlorination of glycerol with muriatic acid is shown in Fig. 6 while, Figs. 7 and 8 showed effect of those temperatures on the conversion reaction and the product selectivity, respectively.

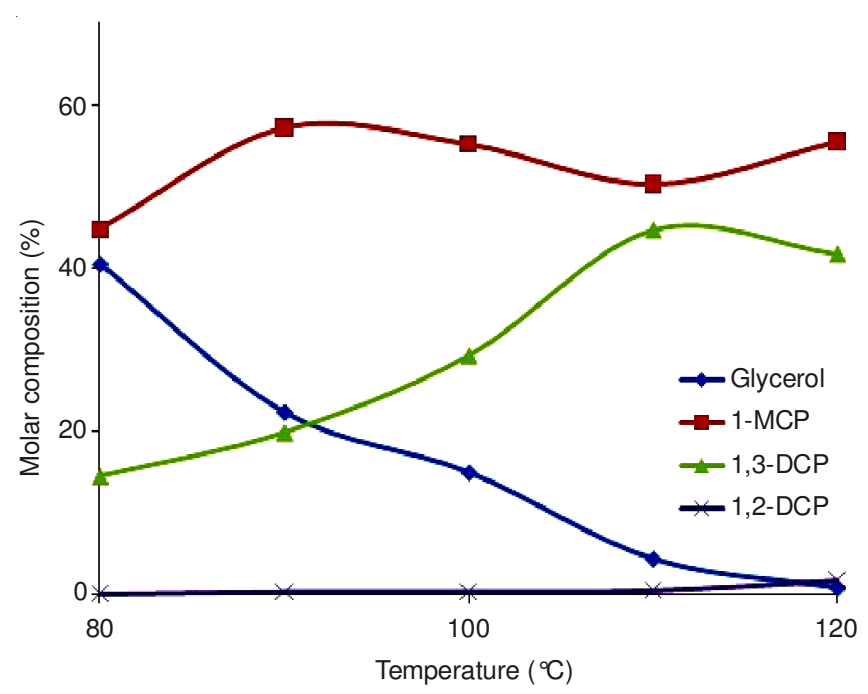

Fig. 6. Effect of temperature on hydrochlorination of glycerol

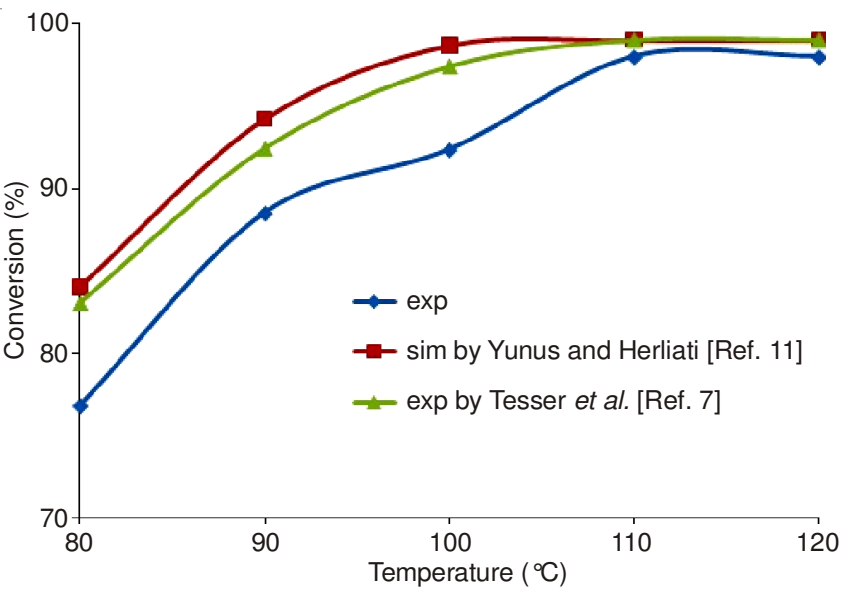

Fig. 7. Effect of temperature on conversion of glycerol

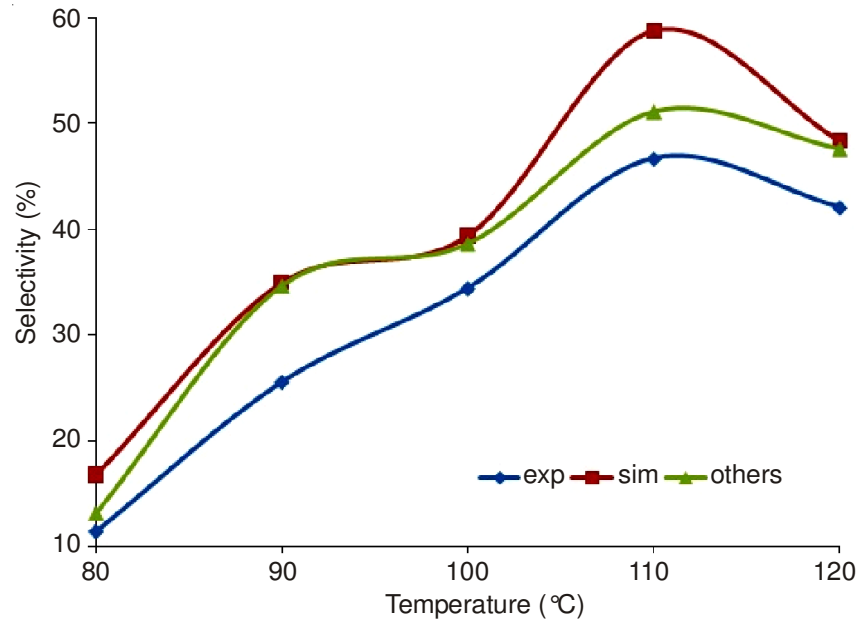

Fig. 8. Effect of temperature on selectivity of 1,3-DCP

As predicted by the simulation reported by Yunus and Herliati ${ }^{11}$ both conversion of glycerol and yield of 1,3-dichloropropanol increases with temperature until it reached the 
TABLE-7

GC/MS ANALYSIS OF PRODUCT AT OPTIMUM CONDITIONS (REACTION TIME: 3 h; TEMPERATURE: $110^{\circ} \mathrm{C}$; CATALYST/MALONIC ACID/ $8 \%$ BY mol; MOLAR RATIO HCl/GLYCEROL : 24:1)

\begin{tabular}{|c|c|c|c|c|}
\hline \multicolumn{4}{|c|}{ Product distribustion in mol (\%) } & \multirow{2}{*}{ Yield for 1,3 DCP (\%) } \\
\hline 1,3-DCP & 1,2-DCP & 1-MCP & Glycerol & \\
\hline 43.09 & 0.23 & 55.72 & 0.96 & 43.09 \\
\hline
\end{tabular}

optimum value. Tesser et al. $^{7}$ also reported the same optimum value at $110{ }^{\circ} \mathrm{C}$. Above this temperature, the yield of 1,3dichloropropanol had dropped markedly while the yield of 1monochloropropanol had increased and the conversion remained constant. Those two figures also showed similar trend even though the result is slightly lower than those reported in literatures.

Quality of the product: The quality of optimized product was verified by GC/MS analysis. The product analysis at optimum conditions (reaction time: $3 \mathrm{~h}$; temperature: $110{ }^{\circ} \mathrm{C}$; catalyst:malonic acid ( $8 \%$ by mol); molar ratio $\mathrm{HCl}$ :Glycerol, 24:1), as depicted in Table-7. Product contained the greatest quantity of monochloropropanol (1-MCP) which was $55.7 \%$, whereas 1,3-dichloropropanol (1,3 DCP) was also the dominant product $(43.1 \%)$. The conversion of glycerol into 1,2-dichloropropanol $(0.23 \%)$ was also observed. The final optimized product also contained trace, amount of glycerol (0.96\%). Lastly, GC/MS analysis indicated that optimized product was successfully converted to almost $100 \%$ of desired product.

\section{Conclusion}

In this study, several experiments were conducted to synthesize dichloropropanol from bio-based glycerol via hydrochlorination process using aqueous hydrochloric acid $37 \%$ (muriatic acid). Three process parameters were examined namely types of catalyst, effect of mol ratio and effect of temperature. Among the four selected carboxylic acid catalysts chosen for the screening, the best catalyst in terms of activity and selectivity was malonic acid. Its low volatility ensures minimum losses during the hydrochlorination process. The most favorable molar ratio of $\mathrm{HCl}$ :glycerol was at 24:1 while the optimum operating temperature for the reaction was at $110^{\circ} \mathrm{C}$. These experimental results, which used muriatic acid
(37\% aqueous hydrochloric acid) as a chlorination agent for hydrochlorination of glycerol were comparable to the conventional methods using gaseous hydrogen chloride. In conclusion, the optimal reaction conditions obtained so far are as follows: reaction time: $3 \mathrm{~h}$; temperature: $110^{\circ} \mathrm{C}$; catalyst: malonicacid ( $8 \%$ by mol); molar ratio $\mathrm{HCl}$ :glycerol::24:1. With some improvement on the conditions using aqueous hydrogen chloride as a hydroclorination agent, it is believed that this proposed technology can be considered as a viable approach. The use of aqueous $\mathrm{HCl}$ (muriatic acid) is low cost and very much safer compared to gaseous $\mathrm{HCl}$.

\section{REFERENCES}

1. J.S. Zhang, Y.C. Lu, Q.R. Jin, K. Wang and G.S. Luo, Chem. Eng. J., 203, 142 (2012).

2. N. Nagato, H. Mori, K. Maki and R. Ishioka, US Patent 4634784 (1987).

3. S.H. Lee, D.R. Park, H. Kim, J. Lee, J.C. Jung, S.Y. Woo, W.S. Song, M.S. Kwon and I.K. Song, Catal. Commun., 9, 1920 (2008).

4. Y. Zheng, X. Chen and Y. Shen, Chem. Rev., 108, 5253 (2008).

5. M. Mccoy, Chem. Eng. News, 84, 7 (2006).

6. W.J. Kruper Jr., T. Arrowood, B.M. Bell, J. Briggs, R.M. Campbell, B.D. Hook, A. Nguyen, C. Theriault and R. Fitschen, US Patent 2008/ 0015369A1 (2008).

7. R. Tesser, E. Santacesaria, M. Di Serio, G. Di Nuzzi and V. Fiandra, Ind. Eng. Chem. Res., 46, 6456 (2007).

8. K. Philippe, C. Franck, D. Andolenko and R. Veyrac, WIPO WO2007/ 054505A2 (2007).

9. K. Philippe, P. Gilbeau, B. Gosselin and S. Claessens, US Patent 2007/ 0112224A1 (2007).

10. A.A. Kiss, H.J. Vos, E.H. Renkema and A.J.B.T. Kate, US Patent 20120108856 (2012).

11. R. Yunus and A.S. Herliati, Inter. J. Chem., 3, 196 (2011).

12. C. Jonathan, N.G.S. Warren and P. Wathers, Organic Chemistry, Oxford University Press, Oxford, UK (2001).

13. D. Siano, E. Santacesaria, V. Fiandra, R. Tesser, G.D. Nuzzi, M.D. Serio and M. Nastasi, WIPO: WO111810A2 (2006).

14. K. Pavel, S. Petr and B. Ivana, WIPO: WO2005/021476A1 (2005). 